\title{
BASELINE AND OPTIONAL BENCH-SCALE TESTING OF A CHEMICAL CANDLE FILTER SAFEGUARD DEVICE
}

\author{
Final Topical Report \\ Bench-Scale Testing) \\ Prepared for: \\ AAD Document Control \\ U.S. Department of Energy \\ National Energy Technology Laboratory \\ PO Box 10940, MS 921-143 \\ Pittsburgh, PA 15236-0940 \\ Cooperative Agreement No. DE-AC26-99FT40677 \\ Performance Monitor: Ted McMahon
}

(including Task 2 - Detailed Test Plan for Task 5 Bench-Scale Testing and the Plan for Optional

Prepared by:

John P. Hurley Michael L. Swanson

Energy \& Environmental Research Center University of North Dakota

PO Box 9018

Grand Forks, ND 58202-9018 


\section{DOE DISCLAIMER}

This report was prepared as an account of work sponsored by an agency of the United States Government. Neither the United States Government, nor any agency thereof, nor any of their employees makes any warranty, express or implied, or assumes any legal liability or responsibility for the accuracy, completeness, or usefulness of any information, apparatus, product, or process disclosed or represents that its use would not infringe privately owned rights. Reference herein to any specific commercial product, process, or service by trade name, trademark, manufacturer, or otherwise does not necessarily constitute or imply its endorsement, recommendation, or favoring by the United States Government or any agency thereof. The views and opinions of authors expressed herein do not necessarily state or reflect those of the United States Government or any agency thereof.

This report is available to the public from the National Technical Information Service, U.S. Department of Commerce, 5285 Port Royal Road, Springfield, VA 22161; phone orders accepted at (703) 487-4650.

\section{ACKNOWLEDGMENT}

This report was prepared with the support of the U.S. Department of Energy (DOE) National Energy Technology Laboratory Cooperative Agreement No. DE-AC26-99FT40677. However, any opinions, findings, conclusions, or recommendations expressed herein are those of the authors(s) and do not necessarily reflect the views of DOE.

\section{EERC DISCLAIMER}

LEGAL NOTICE This research report was prepared by the Energy \& Environmental Research Center (EERC), an agency of the University of North Dakota, as an account of work sponsored by DOE. Because of the research nature of the work performed, neither the EERC nor any of its employees makes any warranty, express or implied, or assumes any legal liability or responsibility for the accuracy, completeness, or usefulness of any information, apparatus, product, or process disclosed, or represents that its use would not infringe privately owned rights. Reference herein to any specific commercial product, process, or service by trade name, trademark, manufacturer, or otherwise does not necessarily constitute or imply its endorsement or recommendation by the EERC. 


\section{TABLE OF CONTENTS}

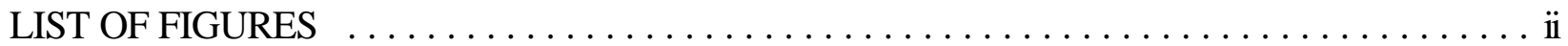

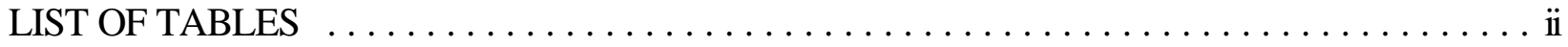

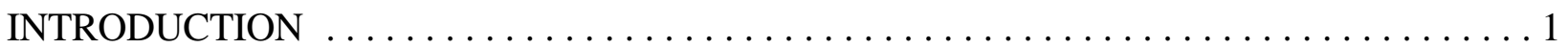

TASK 5 AND OPTIONAL BENCH-SCALE TEST PLAN $\ldots \ldots \ldots \ldots \ldots \ldots \ldots \ldots \ldots \ldots \ldots$

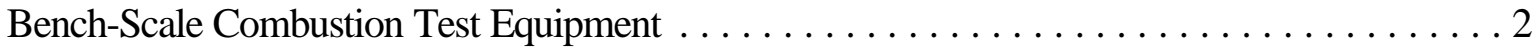

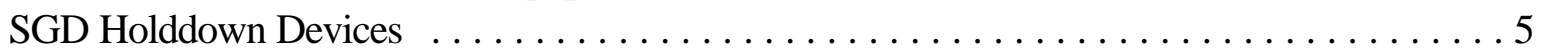

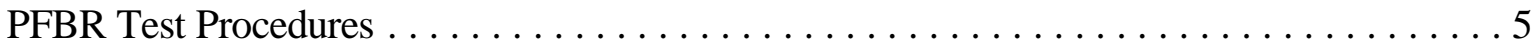

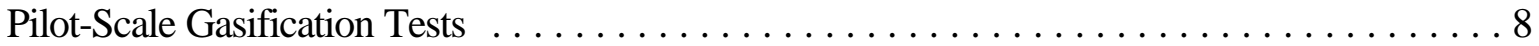

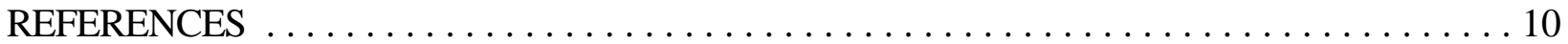




\section{LIST OF FIGURES}

1 Schematic of the PFBR with the hot-gas filter vessel in place. . . . . . . . . . . . 3

2 Existing EERC tube sheet with backpulse and pressure tap nozzles $\ldots \ldots \ldots \ldots \ldots$

3 EERC safeguard device design - Variation $1 \ldots \ldots \ldots \ldots \ldots \ldots \ldots \ldots \ldots \ldots \ldots \ldots \ldots$

4 EERC safeguard device design - Variation $2 \ldots \ldots \ldots \ldots \ldots \ldots \ldots \ldots \ldots \ldots \ldots \ldots$

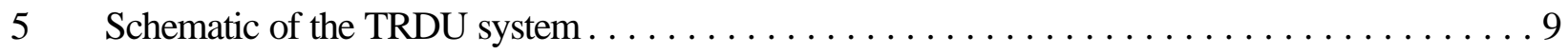

\section{LIST OF TABLES}

1 Typical PFBR Operating Conditions $\ldots \ldots \ldots \ldots \ldots \ldots \ldots \ldots \ldots \ldots \ldots \ldots \ldots \ldots \ldots \ldots \ldots \ldots$

2 High-Temperature, High-Pressure Bench-Scale Filter Vessel

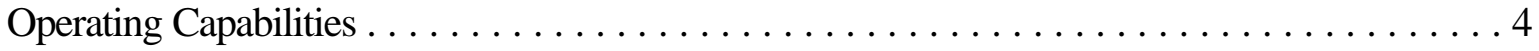




\section{DEVELOPMENT OF A CHEMICAL CANDLE FILTER SAFEGUARD DEVICE}

\section{INTRODUCTION}

This project was undertaken by the Energy \& Environmental Research Center (EERC) to design, construct, and test the feasibility of a hot-gas filter safeguard device (SGD) to prevent the release of dust in the event of candle filter failure under both pressurized fluidized-bed combustion (PFBC) (oxidizing) and integrated gasification combined cycle (IGCC) (reducing) operating conditions. The SGD must use existing filter system seals, gaskets, fixtures, and assemblies as much as possible. It must also activate quickly when a candle filter has failed, preferably preventing dust concentrations downstream of the SGD from exceeding 1 ppmw. ${ }^{1}$ In addition, the SGD must be able to operate in an inactive mode with minimal pressure drop, and its operation cannot be affected by repeated backpulse cleaning events of up to 3 psia and $1 / 2$ second in duration.

The EERC concept for the design was to use our extensive knowledge of the factors that make filter dust sticky at gas filtration temperatures to make an inexpensive SGD that employs a sticky yet thermodynamically stable coating on a highly porous ceramic substrate. The SGD would be placed at the outlet of a candle filter. The high porosity of the SGD would create a very low pressure drop across the device and permit reverse pulse cleaning directly through the SGD. Normally, such an open structure would also allow filter dust particles flowing through a broken candle filter to also easily pass through the SGD. However, in our concept, the sticky surface of the device will rapidly and permanently trap dust particles, causing the device to irreversibly plug upon failure of a filter. Just as different filter materials are used for combustion versus gasification conditions, different coatings will be used on an inert ceramic substrate to cover the typical range of conditions in PFBC (oxidizing) or IGCC (reducing) operating mode. For gasification, conditions in the Westinghouse filter vessel at the Sierra Pacific Piñon Pine plant are being simulated in the testing. For combustion systems, the approximate conditions in the Siemens-Westinghouse particle filter used in conjunction with the Southern Company Services transport reactor being tested at the Wilsonville facility are employed.

The overall design of the EERC SGD is described in detail in the final topical report for Task 1 of this project - Conceptual Design (EERC Document 2000-EERC-08-01). That report was received by DOE in August 2000. The following document serves as the final report for Task 2 - Detailed Test Plan for Task 5 Bench-Scale Testing and the test plan for Option 1 - Additional Bench-Scale Testing. It describes the equipment, fixturing, and test procedures that will be used to gather detailed test data on the performance of the EERC SGD concept in a bench-scale combustor and to gain operational experience in a pilot-scale gasification system.

\section{TASK 5 AND OPTIONAL BENCH-SCALE TEST PLAN}

As described in the final report for Task 1 of this project - Conceptual Design (EERC Document 2000-EERC-08-01), which was received by DOE in August 2000, three different SGD configurations 
are being considered for the combustion tests, with one additional configuration for the gasification tests. Two of the combustion test configurations consist of disks of ceramic sponge material made from zirconia-toughened alumina provided by Porvair-Selee. Each disk is 3 inches in diameter and 1 inch thick. One type will contain 60 pores per inch (ppi) and the other 80 ppi. As described in detail in the Task 1 report, both will be coated with a thermodynamically stable chemical compound that will be sticky toward the filter dust that will enter the SGD upon failure of a candle filter. The third type of combustion SGD will consist of 4-inch-long by 3-inch-diameter sections of PRD-66 candle filter material made without the surface membrane in order to minimize the pressure drop. These radial SGDs were provided by Honeywell Advanced Composites. They will be coated with the same sticky compound as the ceramic sponge disks. Another type of sponge material from Porvair Selee will be used for the pilot-scale gasification tests. It will be 30 ppi silicon dioxide-bonded silicon carbide, coated with a different type of sticky material as described in detail in the Task 1 report.

\section{Bench-Scale Combustion Test Equipment}

The proposed bench-scale tests under combustion conditions will use the pressurized fluidizedbed reactor (PFBR), which has been constructed at the EERC to simulate the bed chemistry, ash interactions, and emissions from a PFB under closely controlled conditions. This reactor has been used for sorbent characterization, gaseous emissions including trace elements, agglomeration, and hot-gas cleanup testing in a cost-effective manner over a wide range of operational conditions. The conditions used during the SGD tests will be very similar to those in the Siemens-Westinghouse particle filter being tested at the Wilsonville facility. The range of operating conditions for the system are listed in Table 1.

\section{TABLE 1}

Typical PFBR Operating Conditions

\begin{tabular}{lc}
\hline Reactor Diameter & 2.875 -inch ID \\
Temperature & $1400 \mathrm{E}-1700 \mathrm{EF}$ \\
Pressure & $0-150 \mathrm{psig}$ \\
Gas Flow Rate & $1-30 \mathrm{scfm}$ \\
Coal Feed Rate & $1-8 \mathrm{lb} / \mathrm{hr}$ \\
Velocity & $1-10 \mathrm{ft} / \mathrm{sec}$ \\
Cyclone Exit Temperature & $1600 \mathrm{EF}$ maximum \\
Particulate Loading & $200-9000 \mathrm{ppm}$ \\
\hline
\end{tabular}

A bench-scale filter vessel will be used in conjunction with the bench-scale PFBR (in combustion mode) to obtain high-temperature, high-pressure operational data on various SGDs. This vessel is 
designed to handle all of the gas flow from the PFBR at its nominal design conditions. The vessel has a 10 -inch ID and is 60 inches long (including cone, vessel, and cap) and can handle a gas flow up to 30 $\mathrm{scfm}$ at $1550 \mathrm{EF}$ and $150 \mathrm{psig}$. The tube sheet is interchangeable to handle different-sized filters or SGDs. The filters are currently sealed in an uncooled tube sheet with a bolted metal plate and Nextel fiber gaskets which counteract the upward force imparted across the candle filter by the filter's differential pressure. A schematic of the PFBR and filter vessel is shown in Figure 1.

A new uncooled tube sheet has been designed and constructed under a separate project to optimize the SGD installation and sealing in the Task 5 and optional testing. It is shown in Figure 2. It is 2 inches thick with three hemispherical openings for the candle filters, along with holddown plates to seal the candle filters in place. Holes are drilled through the side of the tube sheet to allow pressure tap measurements between the candle filter and the SGD and potentially to allow gas to be backpulsed between the filter and SGD if desired. Two additional differential pressure transmitters have been added to the data acquisition and control system to permit measurements of pressure drops across both the candle filter and the SGD. The vessel is sized such that it could handle three candle filters up to 18" long with a 2.375-inch OD. This would provide candle space of 3.85-inch center line to center line and enable filter face velocities as low as $3 \mathrm{ft} / \mathrm{min}$ to be tested in the PFBR. Higher face velocities would be achieved by using shorter or fewer candles or moderately higher gas flow rates, although plans are to use three candle filters. For the Task 5 and optional testing, three 15-inch candle filters and SGDs will be placed in the filter vessel for evaluation. Operating conditions for the filter vessel are shown in Table 2. Ports are available in the filter vessel for temperature and pressure measurements.

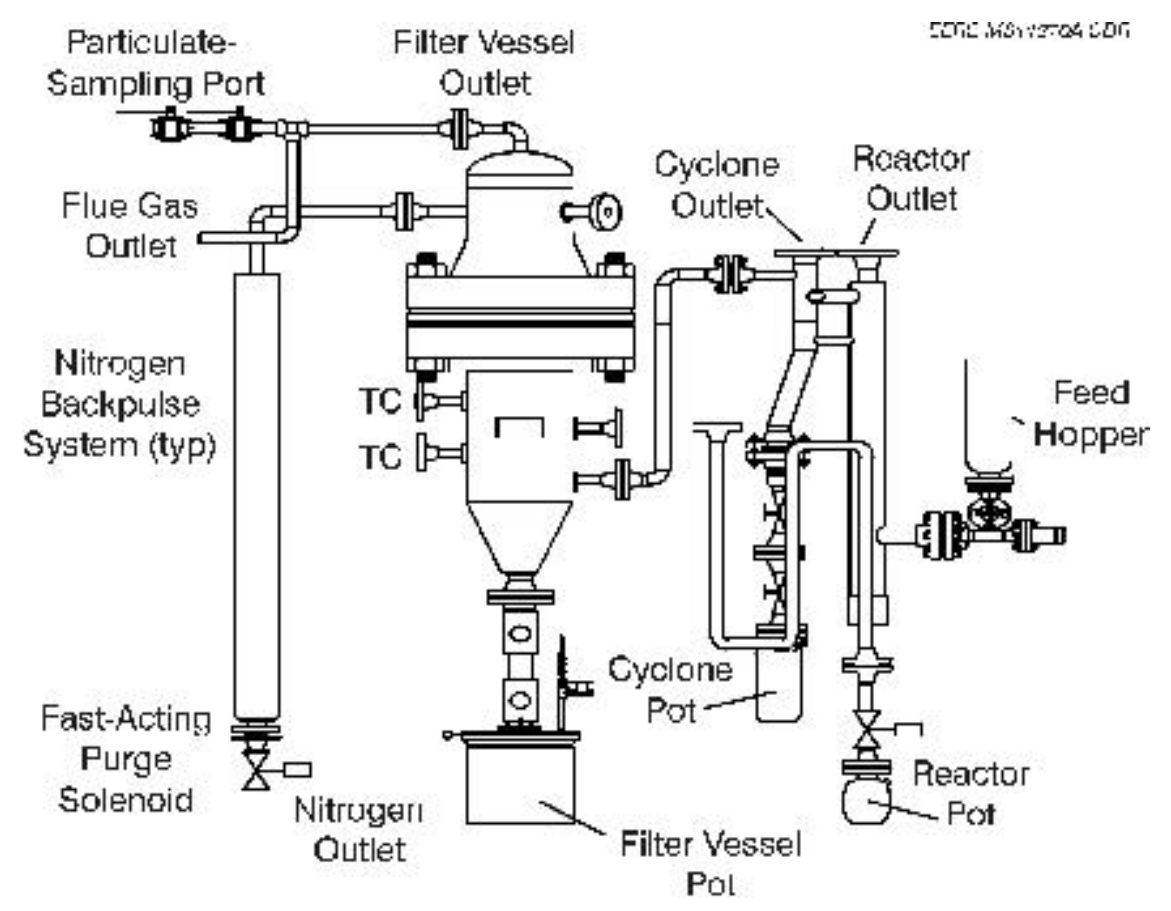

Figure 1. Schematic of the PFBR with the hot-gas filter vessel in place. 


\section{TABLE 2}

\section{High-Temperature, High-Pressure Bench-Scale Filter Vessel Operating Capabilities}

\begin{tabular}{ll} 
Vessel Diameter & 10 -inch ID \\
Temperature & $1450 \mathrm{EF}$ \\
Pressure & $150 \mathrm{psig}$ \\
Gas Flow Rate & Up to $30 \mathrm{scfm}$ \\
Filter Size & 2.375 -inch OD by 15 inches long \\
Filter Face Velocity & $4 \mathrm{ft} / \mathrm{min}$ \\
$\mathrm{N}_{2}$ Backpulse System & Room temperature with either short, high-pressure or \\
& long, low-pressure pulses \\
\hline
\end{tabular}

The nitrogen backpulse system is designed to supply a minimum of three candle volumes per pulse. The nitrogen is capable of being heated up to $1500 \mathrm{EF}$ before entering the filter vessel; however, it is expected that room temperature backpulse nitrogen will be used in this program.

An Analog Devices ${ }^{\mathrm{TM}}$ data acquisition and control system using Iconics Genesis ${ }^{\mathrm{TM}}$ software is used to monitor and record all critical pressures, temperatures, flow rates, and emissions. These critical data include the gas flow rates, bed static pressure and differential pressures across the bed and filter

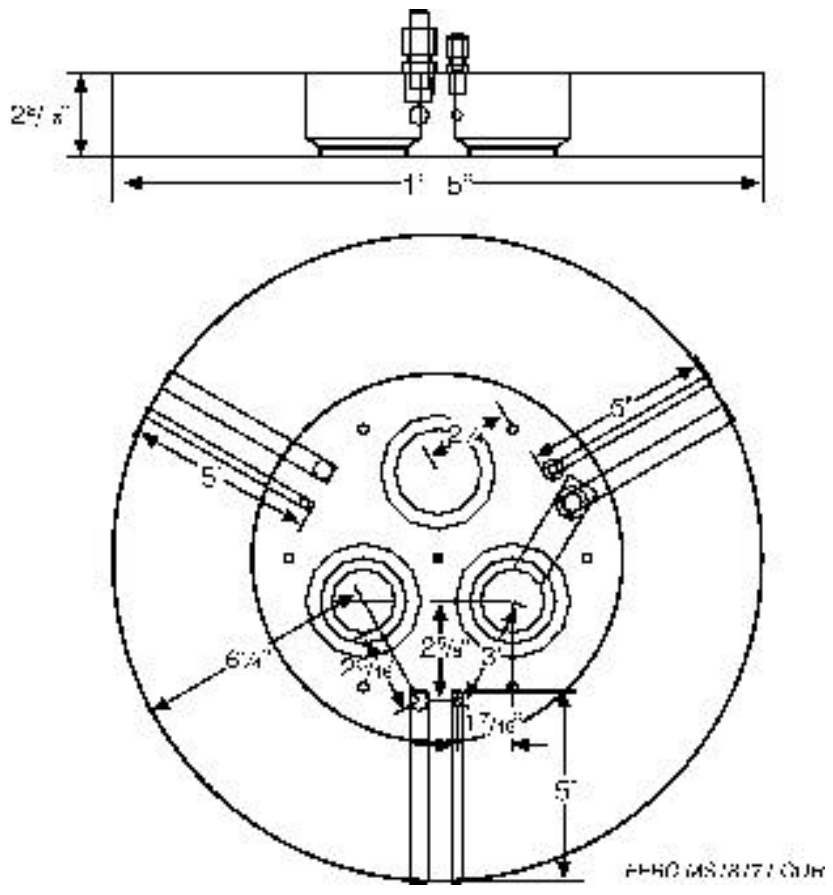

Figure 2. Existing EERC tube sheet with backpulse and pressure tap nozzles. 
vessel, and eleven different internal reactor temperatures and six different hot-gas filter vessel temperatures. These data points are saved every 30 seconds. The data acquisition software will be modified to acquire important transient pressure information such as differential pressure across the candle filter and SGD at 1-second intervals during backpulsing. The air and nitrogen flow rates are controlled automatically to flow rate set points. The reactor pressure is automatically controlled to a pressure set point. Continuous emissions sampling of the flue gas measures the levels of $\mathrm{O}_{2}, \mathrm{SO}_{2}, \mathrm{NO}_{\mathrm{x}}$, $\mathrm{N}_{2} \mathrm{O}, \mathrm{CO}, \mathrm{CO}_{2}$, and hydrocarbon. Solid samples can include bottom ash, fly ash, and particulate samples from the stack to determine the particulate loading leaving the filter vessel.

\section{SGD Holddown Devices}

As described above, two main types of SGDs will be tested. One type will consist of ceramic sponge disks 3 inches in diameter and 1 inch thick. The other will be cylinders consisting of pieces of uncoated candle filter 4 inches long and 3 inches in diameter. The SGDs will be attached to the holddown plates used to seal the candle filters in the tube sheet. The ceramic foam material will be sealwelded in a metal cylinder to the holddown plate. It will be supported with coarse backup metal plates that support the weaker foam material during high pressure drop periods such as a backpulse or in the event the candle filter has failed with the SGD operating at the full filter system pressure drop. This first design is shown in Figure 3 and consists of the 3-inch-diameter coated ceramic foam material inserted into a metal cylinder manufactured from 3-inch Schedule 40 pipe and sealed around the outside of the foam with either Interam intumescent mat material or with a compressed layer of glass fiber Koalwool. The foam SGD is also held in place with gaskets of Interam gasket material on the top of the upper coarse metal support disks. The Interam gasket material expands upon heating to ensure that the foam material will remain sealed in the metal cylinder even with the differences in the expansion coefficients between the metal cylinder and the ceramic foam.

The second design which uses a section of a PRD-66 candle filter that is clamped between the filter holddown plate and a cover plate is shown in Figure 4. Both plates are grooved to hold Interam gaskets to seal both ends of the SGD. The intumescent Interam gaskets ensure the candle material remains sealed at both ends even with the difference in expansion coefficients between the holddown bolts and the candle material. A shroud around the fail-safe directs the backpulse gas through the sides of the candle filter since the top of the SGD is blocked by the cover plate. The EERC will fabricate the necessary holddown devices in the EERC machine shop.

\section{PFBR Test Procedures}

The three main combustion SGD designs will be tested during three separate PFBR baseline tests. The SGDs will be the $60 \mathrm{ppi}$ and 80 ppi zirconia-toughened alumina ceramic sponge materials provided by Porvair-Selee and the PRD-66 cylinders provided by Honeywell Advanced Ceramics. Three SGDs of a single design will be used in each test. One SGD will be placed above each of the three candle filters, and the system operated for two days during each baseline test. The best performing design of the initial three will be further tested under the optional testing portion of the program. 


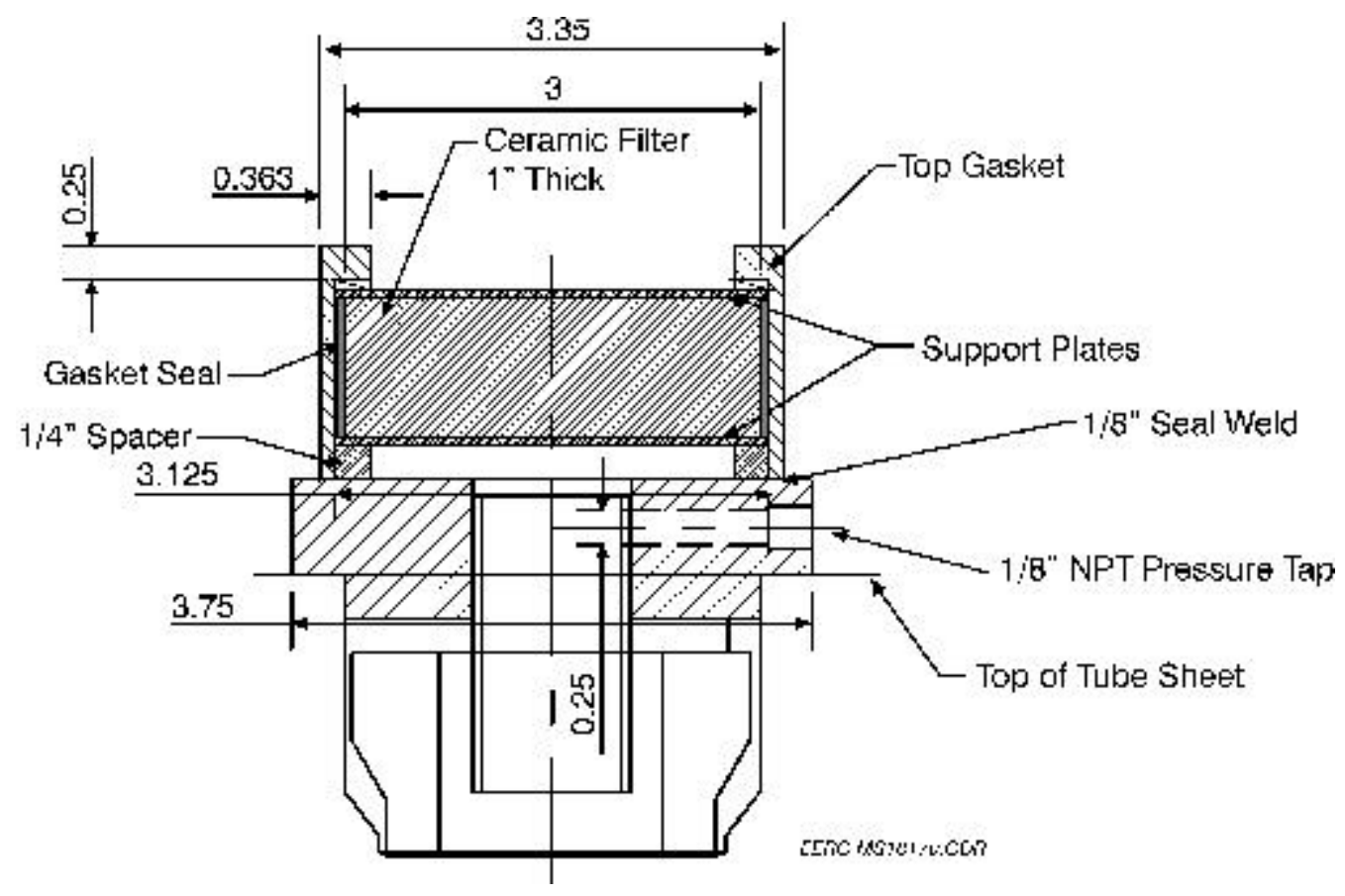

Figure 3. EERC safeguard device design - Variation 1.

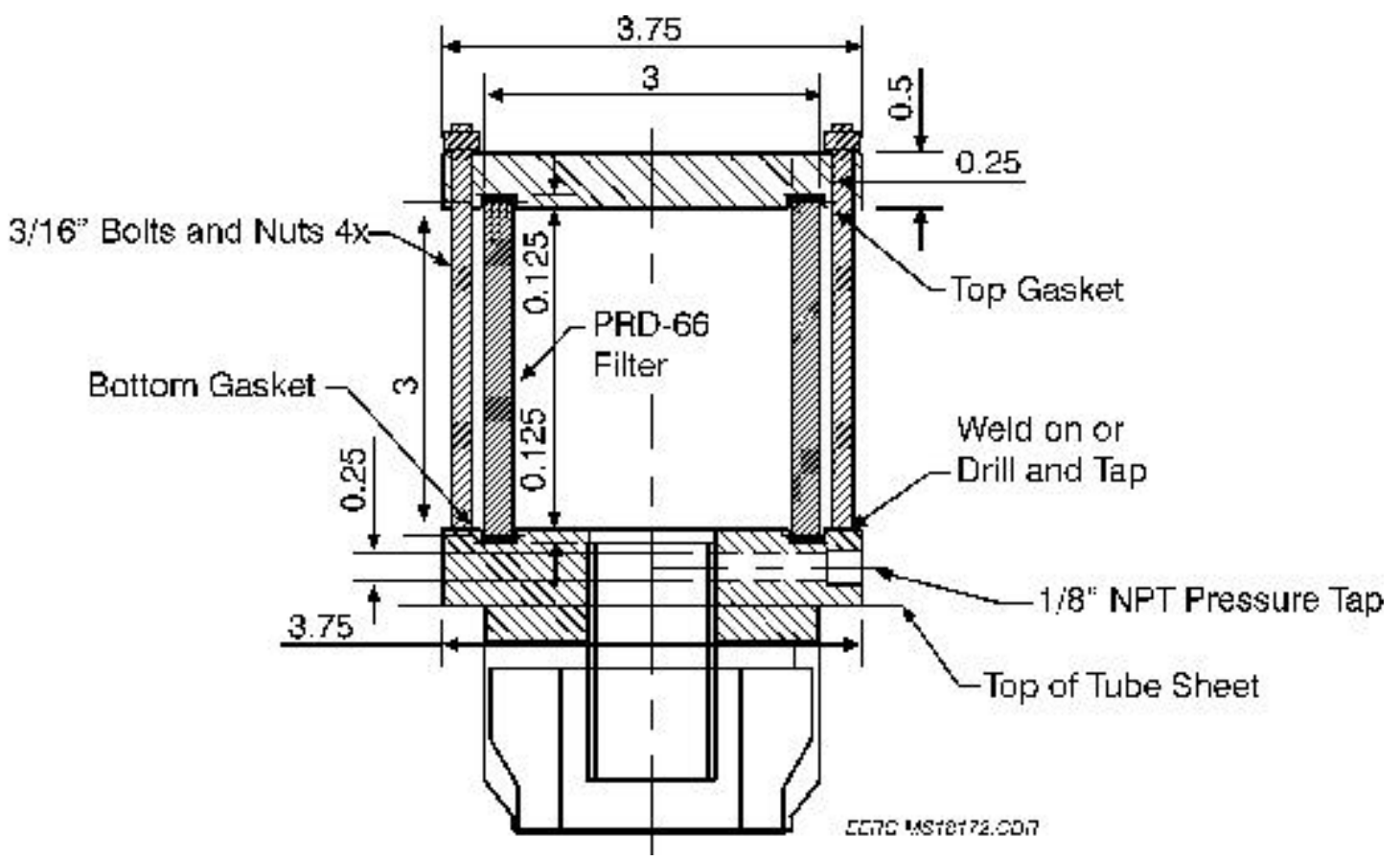

Figure 4. EERC safeguard device design - Variation 2. 
Three different performance parameters of the SGD performance will be measured over each 2day test. The first parameter will be unactivated pressure drop. This will be determined by measuring the pressure drops across each candle filter and the SGD on top of each filter at ambient temperatures and face velocities of 4, 7, and $10 \mathrm{ft} / \mathrm{min}$. This test will then be repeated at system temperatures of $1000 \mathrm{E}$ and 1400EF. The second measurement will demonstrate under actual hot-gas operating conditions the SGD operability under the inactive mode of operation. During this phase of the test, the system will run continuously for 24 hours. During this time, flue gas and fly ash will be generated by burning coal in the PFBR. The following parameters will be monitored during this portion of the test:

- Pressures in the dirty gas inlet and clean gas plenum and the differential pressure across the tube sheet and in the cavity between two filters and its associated SGD

- The transient pulse pressures in the cavities

- Backpulse gas operating conditions and gas consumption

- Interval between backpulses

- Outlet dust loadings, collected using U.S. Environmental Protection Agency (EPA) Method 5

Operation will be conducted with the following backpulse conditions:

- One pulse of room temperature nitrogen per candle, nominally of 500-ms duration.

- Pulse pressures in the cavities of up to 3 psia above inlet (dirty gas) pressure.

- Initiation of backpulse when the candle filter reaches the preselected level of a 30-minute time interval, although shorter periods would be selected if the filter differential pressure increased more than 3 psid.

The third portion of each 2-day baseline test will demonstrate the effectiveness of the SGD when a candle filter fails. Following the completion of the unactivated test, a drill bit welded on a stainless steel shaft will be inserted through a thermocouple port specifically modified to accommodate the shaft insertion during operation to break or drill a hole in one of the candle filters. This will allow the SGD in this candle to be activated while in operation with the other filter(s) handling the increased load once the SGD has plugged. The pressure drop across the filter as a function of time and the time required to plug the filter will be measured. The system will be run through several pulse cycles over an 8-hour period to demonstrate the ability of the SGD to retain a permanent dust seal. If the first SGD has activated properly after 8 hours, a second candle filter will be broken in a similar manner, and the SGD's performance in the activated mode will also be measured. If the SGD has not activated properly, the test will be continued to determine if the SGD has reached a stable dust penetration rate. In addition to the pressure drop data, several EPA Method 5 particulate tests will be conducted to characterize the particle-size loading and distributions at the outlet of the filter/SGD as a function of time. The results 
from each test will include a fractional collection efficiency curve, pressure drop across the SGD as a function of time, and mass that passes through the filter/SGD.

Upon completion of the tests of the initial three designs under the Task 5 baseline testing, at least one additional 2-day test will be run on the best performing SGD design under the optional testing program. The optional test parameters will be decided in cooperation with the DOE COR. If one of the early prototypes is very successful, a potential test plan variation could be to test the SGD at an operating temperature different from the optimum determined in the laboratory to allow the SGD operating temperature window to be identified. Other possible tests may include changes in the SGD design such as the physical characteristics of the porous ceramic substrate or the thickness of the sticky coating layer.

\section{Pilot-Scale Gasification Tests}

Funding levels for the program are insufficient to permit detailed bench-scale tests of the gasification SGD as well as for the combustion SGD. However, the EERC has available a pilot-scale gasification facility which is being operated under separate DOE funding in which the gasification SGD can be placed during normal operation. These tests will not provide the detailed performance data such as will be gathered from the bench-scale tests of the combustion SGD, but will provide some operational experience and proof-of-concept information.

The filter system in the EERC pilot-scale gasification system simulates the higher- temperature filter systems such as the one being operated at the Sierra Pacific Piñon Pine Station. The gasifier is known as the Transport Reactor Development Unit or TRDU. A schematic of the system and filter vessel is shown in Figure 5. The gasification SGD will be exposed in the filter vessel during ongoing TRDU runs being funded by DOE NETL through a separate contract "Advanced High-Temperature, High-Pressure Transport Reactor Gasification Program." Funding from the SGD program will only be used to place and retrieve the SGDs when the vessel is opened as part of normal operation of the system. In addition, funding from the SGD program will be used to analyze the exposed SGDs to determine if they plugged during normal operation.

It is expected that two SGDs for reducing conditions will be exposed in the filter vessel by placing them above the candle filters to demonstrate their suitability in the inactive phase. By examining the SGDs before and after a TRDU run, we will be able to determine the stability of the sticky coatings and whether the SGD plugs during normal operation.

A typical TRDU test will expose the SGD to approximately 200 hours of gas and dust at $1000 \mathrm{EF}$ and 120 psig. During this period, the following parameters will be monitored:

C Pressures in the dirty gas inlet and clean gas plenum

C Inlet and outlet particulate loadings 


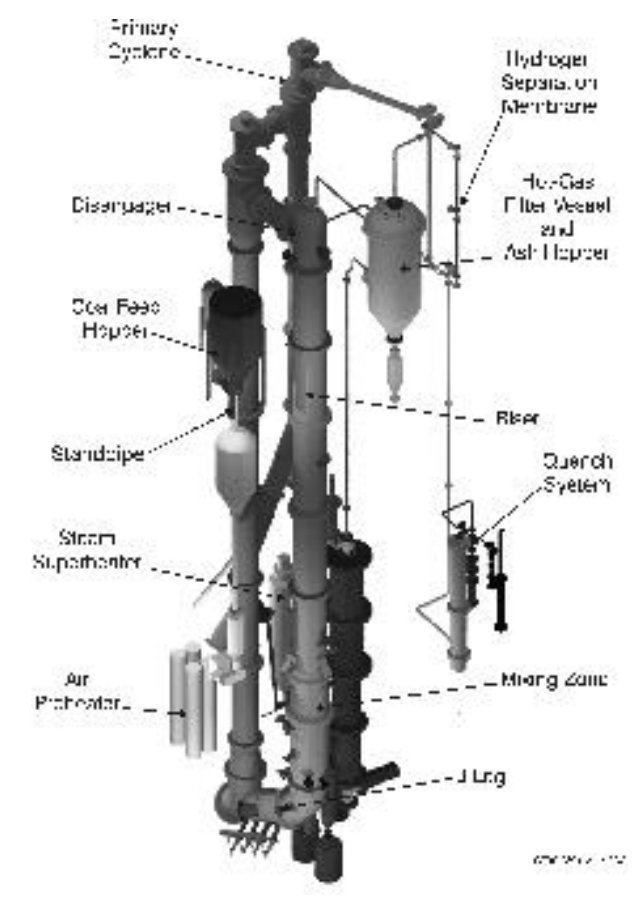

Figure 5. Schematic of the TRDU system.

C Backpulse gas operating conditions and gas consumption

C Interval between backpulses

C Inlet and outlet dust loadings collected using EPA Method 5

Operation will be conducted with the following backpulse conditions:

C One pulse of room temperature nitrogen per candle, nominally of $500 \mathrm{~ms}$ duration

C Pulse pressures in the cavities of up to 3 psia above inlet (dirty gas) pressure

C Initiation of backpulse when the candle filter reaches a preselected level, of either pressure drop, tentatively, 3 psid, or time interval, tentatively, 30 minutes.

Two of the gasification SGDs using the 30-ppi silicon carbide sponge disks (Variation 1) will be tested in the pilot-scale gasification tests. At the completion of the combustion and gasification test programs, a topical report detailing the results of the testing will be prepared. The report will include details of the test conditions, test results, and evaluation of the test results. Also included will be 
recommendations for potential pilot-scale testing of the best-performing SGD design in the SiemensWestinghouse particle filter in use at the Wilsonville facility in Alabama.

\section{REFERENCES}

1. Lippert, T.E.; Bruck, G.J.; Sanjana, Z.N.; Newby, R.A. Westinghouse Advanced Particle Filter System. In Proceedings of the Advanced Coal-Fired Power Systems '95 Review Meeting Vol. I; DOE/METC-95/1018, Vol. 1 (DE95009732), June 1995; pp 123-139. 